\title{
TECHNOLOGICAL AND CROSS-BORDER MIXTURE VALUE CHAIN OF SCIENCE AND ENGINEERING OF MULTI-INTEGRATIVE MECHATRONICS-INTEGRONICS-ADAPTRONICS WITH USE IN THE CONSTRUCTION OF INTELLIGENT SYSTEMS / MICRO-NANO- SYSTEMS
}

\author{
Gh. Ion Gheorghe ${ }^{1}$, Simona Istriteanu ${ }^{2}$ \\ ${ }^{1}$ General Manager-INCD Mechatronics \& Measurement Technique, Bucharest, Associated Prof. in U. Valahia of \\ Târgovişte, U.T.M Bucharest and U. P. Bucharest, Scientific Doctorates Coordinator in Doctoral School of Mechanical \\ Engineering, U. V. of Târgovişte, Corresponding Member of the Academy of Technical Sciences in Romania, \\ geocefin@yahoo.com \\ 2 "Valahia” University- Târgovişte, România, simona.istriteanu@yahoo.com
}

\begin{abstract}
This scientific paper presents in national premiere and in original multi-integrative and multi-potential concept of creation, experimentation, realization and integration on the route of the technological cross-border mixture value chain of intelligent mixmechatronic-integronic-adaptronic products and systems / micro-nano-systems for the industry, economy and society, corresponding to the new intelligent labour jobs.
\end{abstract}

Index Terms: mixture value chain; multi-integrative engineering; mix-mechatronic-integronic-adaptronic products and system

\section{INTRODUCTION}

The scientific paper "Mixture Technological and Cross-Border Value Chain of the Multi-Integrative Science And Engineering of Mechatronics-Integronics-Adaptronics with Use in the Construction of "intelligent systems and micro-nano-systems" is developed in original concept and solution of the author, through innovation and discovery of new scientific, technological, innovative ideas and ideas applied in the mixintegrative-strategic field of and of Mechatronics-IntegronicsAdaptronics, for improving professional skills, efficient operation of adaptive intelligent products, solutions and systems and for the new requirements of the labour market, for the modernization of education quality and high quality processing of technological products, to impose a high level of skills, capabilities and scientific and technical opportunities, focusing the promotion of an advanced high-tech field recognition and appreciation extended to national, European and international level.

This scientific paper sets out the multi-integrative and multipotential concepts of realization, experimentation and mechatronic-integronic-adaptronic systems and micro-nano- systems as future technologies for the development of industry, economy and society today and tomorrow.

This scientific paper emphasizes the scientific creations of the in the mix-integrative-field mechatronics-integronicsadaptronics, for a new generation of a polyvalent multistructural and multi-integrative science for a new global and synthesizer concept forming an adaptive and reproducible integration of real time mechatronic-integronic-adaptronic intelligent information, a synergistic integration of the multidisciplinary field, in philosophy and conception, design and implementation of technical systems and micro-nano-systems and technological complex structures that are based on a high degree of cybernetization and of highly artificial intelligence engineering for a new assembler of intelligent and highly technological structures, for a new intelligent technology with fast and efficient effects on the functioning of processes, processing and products, for promoting new technical solutions for advanced machinery and new equipment for the construction of a new training, synthesized and generative field and for general strategic management of ongoing development of the field and of the interface with other 
engineering types of the safe and effective programme perspectives, etc.

\section{ARCHITECTURE DESCRIPTION OF THE}

CROSS-BORDER MIXTURE VALUE CHAIN OF

\section{SCIENCE AND ENGINEERING OF MULTI- INTEGRATIVE MECHATRONICS-}

\section{INTEGRONICS-ADAPTRONICS}

Technological value chain is linking in a conceptual, constructive and integrative way the new solutions at every stage of the component and contributor of the assembler field of Mechatronics-Integronics-Adaptronics, consolidating thus the integronic multi-structural adaptronic concept and product and the innovative adaptive adaptronic product, all of them in matrices of mix-integrating innovative and solutions.

On each step level are integrated, parts of the whole system, all innovative constructive and technological adaptive solutions, dependent on intelligent manufacturing technologies and innovative solutions advanced adaptive hardware and adaptive software.

Thus, for the component part of the multi-integrative science and engineering - the advanced integrated mechatronic engineering is introduced, in an original, conceptual and mechatronic product with mix innovative integrative mechatronic solutions (Fig. 1).

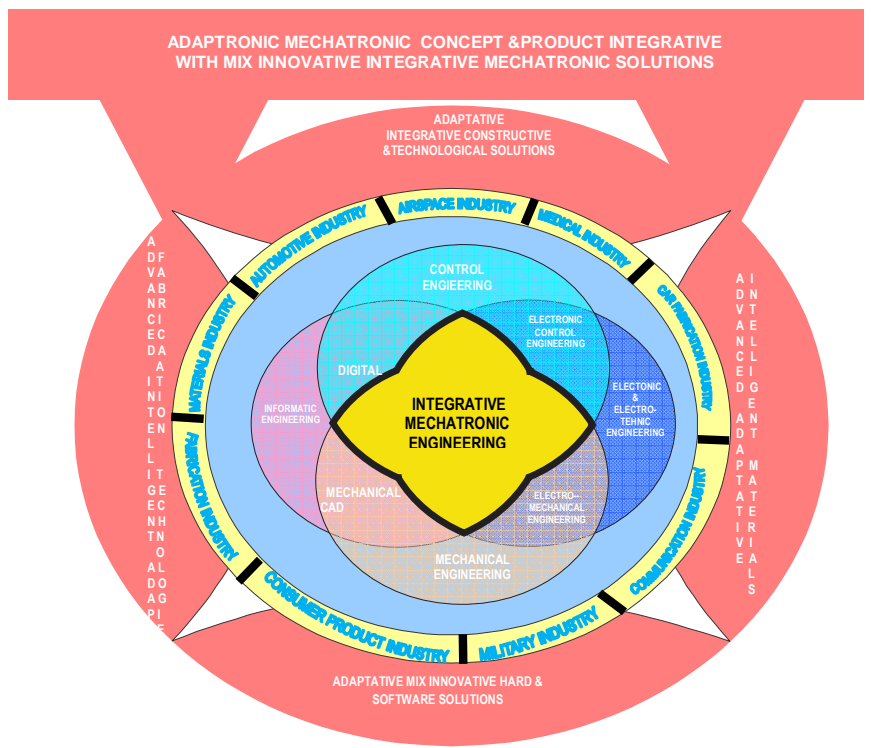

Fig. 1 Integrative mechatronic adaptronic product with mix innovative integrative mechatronic solutions

According to the mentioned picture, the author's patented solution includes structural and functional configuration of the concept and integrator mechatronic product, for employment and place position in the mix-integrative-strategic domain of and of Mechatronics-Integronics-Adaptronics for use and adaptation in intelligent engineering types -mechanics, electronics, computing and integrated control.

The cross-border value chain links for assembly constructive systems, their principles of operation and applied structural modeling in an architectural integrative mix MechatronicsIntegronics-Adaptronics, reinforcing the integronic mechatronic adaptronic concept and product in an intelligent integrative innovative mix-innovative and highly advanced matrix.

For the component of multi-integrative science and engineering - the advanced field of integronic multi-structural engineering, is presented, in an original concept and multistructural integronic adaptronic product mix with innovative integrative itegronic solutions (Fig. 2)

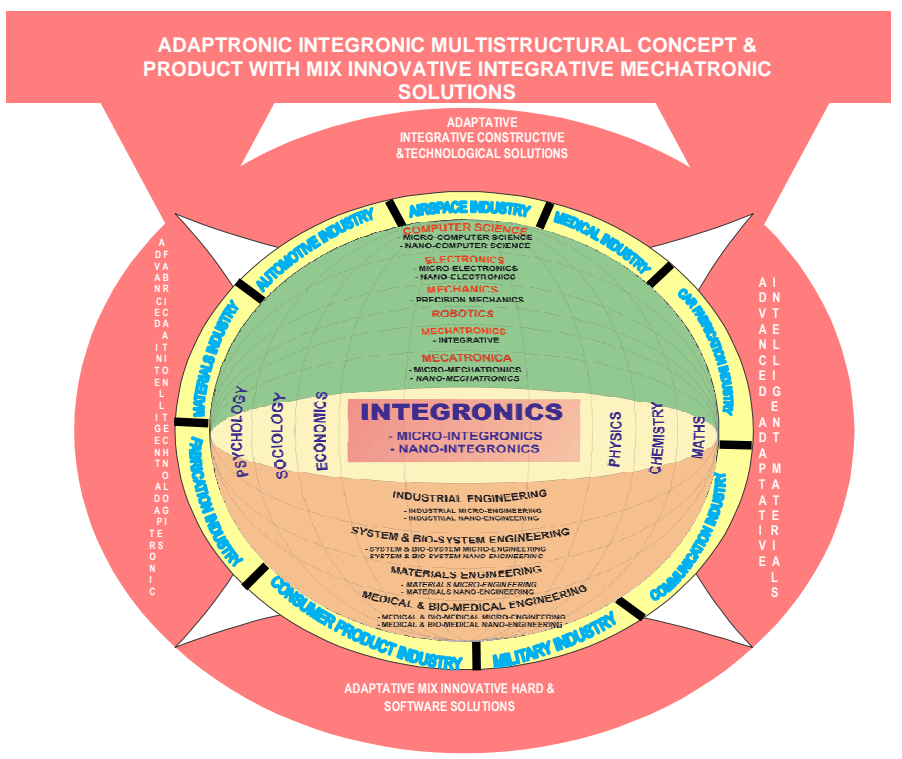

Fig. 2 Adaptronic Integronic Multistructural Concept \& Product with Mix Innovative Integrative Mechatronic Solutions

According to these figures, the author's patented solution includes the structural and multi-functional configuration of the integronic adaptronic multi-structural product and concept, for employment and place position in the value chain of the science and technological domain merging multi-integrative engineering Mechatronics-Integronics-Adaptronics for employment and place position in intelligent engineering types-mechanics, electronics, computing, integrated control and other national sciences. 
The cross-border value chain links for assembly multiconstructive systems, their multi-operation principles and multi-structural multi-applicative modeling in an architectural integrative matrix of mix Mechatronics-IntegronicsAdaptronics, reinforcing the integronic mechatronic adaptronic concept and product in a hyper-intelligent integrative mix-innovative and highly advanced matrix.

For the component of multi-integrative science and engineering-the advanced field of advanced multi-adaptive adaptronic engineering is presented in an original solution the adaptronic multi-adaptive product and concept with mixinnovative adaptive adaptronic solutions (Fig. 3)

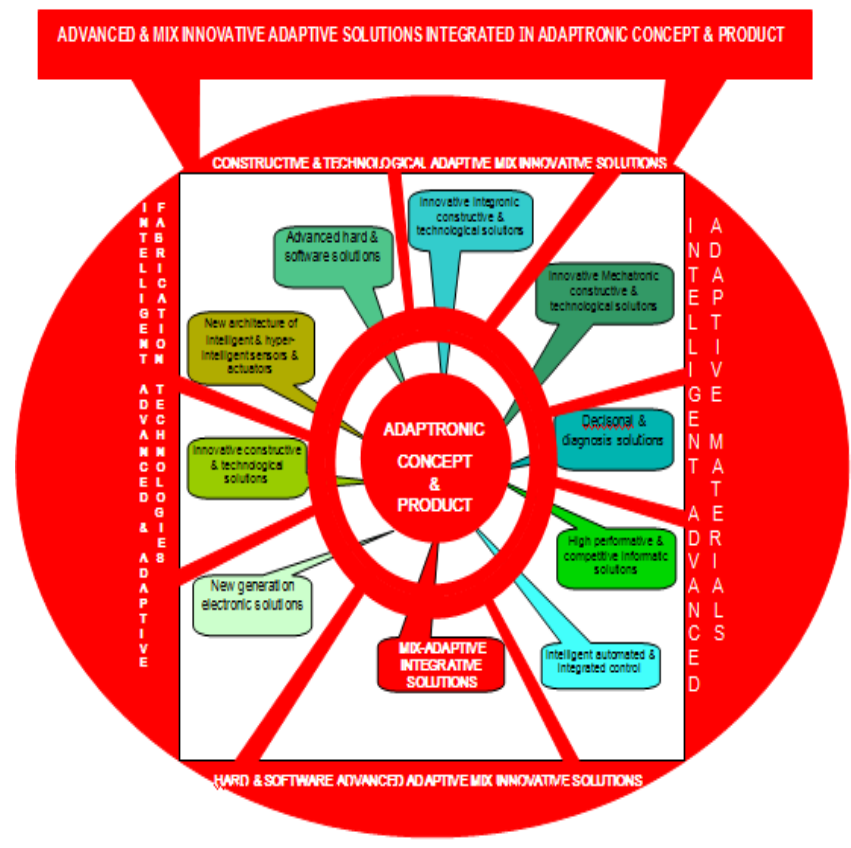

Fig. 3 Adaptronic multi-adaptative concept and product with adaptronic adaptive mix-innovative concept and product

According to the mentioned figure, the author's patented solution includes multi-structural multi-functional and multiadaptive configuration of the adaptronic concept and product intended for employment of position and place in the value chain of scientific domain of the multi-integrative Mechatronics-Integronics-Adaptronics technology and engineering for multi-user and multi-adapting in intelligent engineering types - mechanics / micro-nano-mechatronics, electronics / micro-nano-electronics, computing / micro-nanocomputing, integrated control / integrated micro-nano-control and many other natural sciences and socio-psycho-economic sciences.

The cross-border value chain links for adaptive implementing all multi-poly constructive assemblies, their principles of multi-poly-functionality and modeling / multi-pole-structural processing, multi-pole-applied and adaptive in a "large architectural universe of Mechatronics-IntegronicsAdaptronics", reinforcing thus the integrative mechatronic adaptronic concept and product adaptive in a holonic hyperintelligent and highly advanced mix-innovative multi-polyadvanced multi-poly-assembly.

\section{THE INTEGRATION OF THE CONCEPT OF}

\section{THE VECTOR OF DEVELOPMENT OF NOVELTY - APPLIED ADAPTRONICS}

The integration of the technological and cross-border mixture value chain of science and engineering of multi-integrative Mechatronics - Integronics - Adaptronics describes architecturally the concept on the new developing vector, in the advanced intelligent high-tech areas for decisional adaptation of structures, systems and technologies, in environmental operation requirements.

The new multi-poly-integrated science and engineering «Applicable Adaptronics» (fig. 4), has, in combination and operation, new technologies that have become fundamental such as mechatronics technology, integronic technology, intelligent fabrication technology, simulation and modelling technology, adaptronics technology, electronics technology, software technology, intelligent control technology, signal processing technology, systems and information technology, etc.

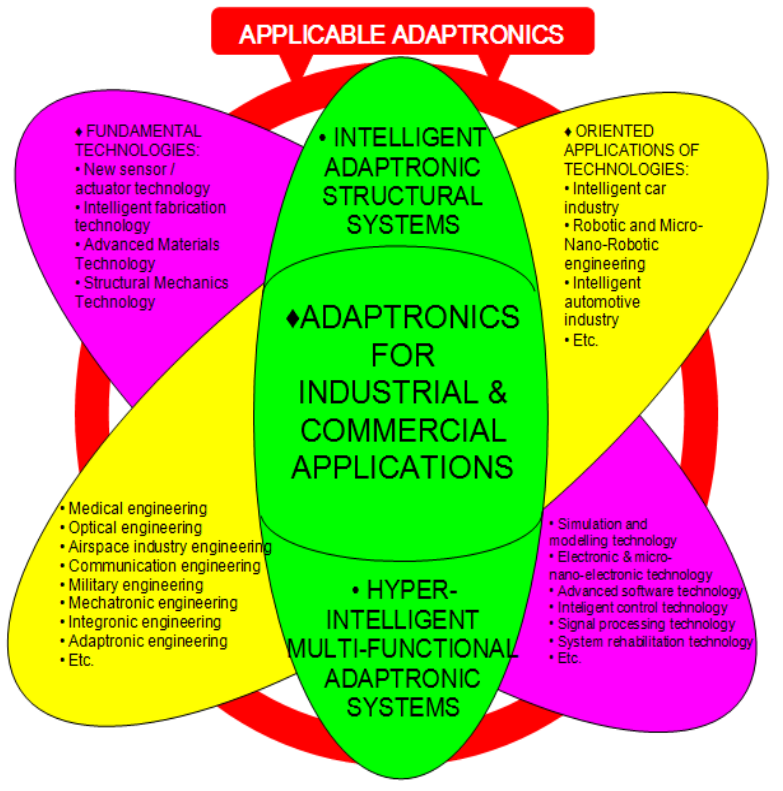

Fig. 4 Applicable Adaptronics

Oriented and adaptive applications of technologies are generally for intelligent machines engineering, robotics engineering, automobile engineering, intelligent aerospace 
engineering, communications engineering, military engineering, mechatronics engineering, integronic engineering, adaptronic engineering, etc..

The constructive / technological / operational and decisional integrated and structurated scientific results of Applicable Adaptronics are objectified in hyper-intelligent adaptronic structural systems used in industrial and commercial applications (see Fig. 5).

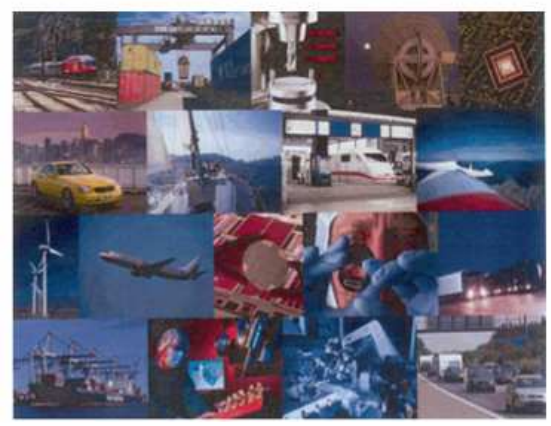

Fig. 5

Applied Adaptronics - as new science, was conceived and developed by several European countries, including Romania, by the National Institute for Research and Development in Mechatronics and Measurement Technique - INCDMTM Bucharest and the author of this work, , who created and developed to maturity the Applied Adaptronics Science and who was created and developed the first Centre for Applied Adaptronics in Romania since 2010, thus bringing a major contribution both nationally and internationally, to the development of advanced intelligent mechatronics, integronics, adaptronics and Applied Adaptronics, as it is highlighted in the scientific book by the same author, entitled "Mechatronics, Integronics and Adaptronics, in 2012.

The new high-tech intelligent adaptive scientific field of Adaptronics \& Applied Adaptronics is defined in the concept of author as a combination and synergy of innovative multitechnology and multi-disciplinary engineering that carries out a mixture of fundamental new knowledge in multi-structural Mechatronics, multi-functional Intgronics, Advanced Intelligent Materials Science, Sensory and Actuatoric Architecture, Computing, Intelligent Measurement Technique and Intelligent Automated Control (fig. 6).

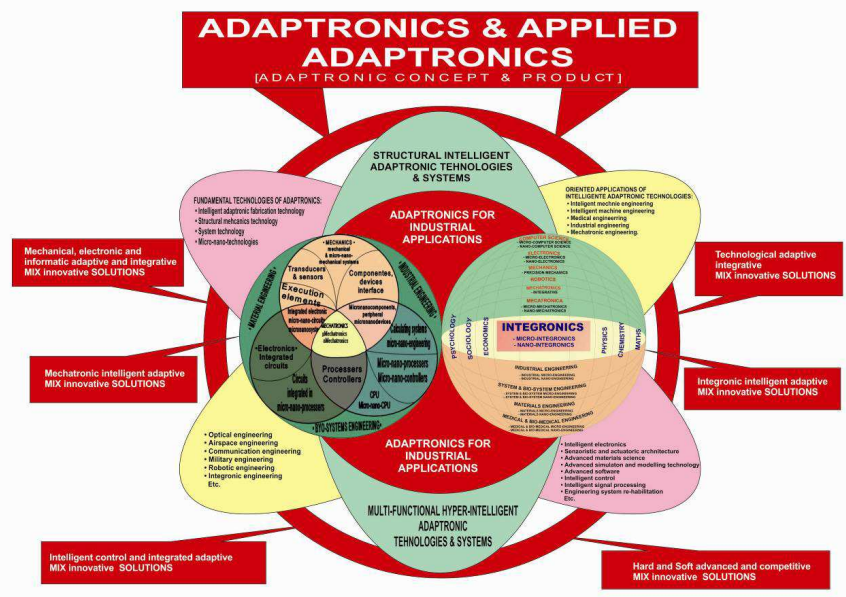

Fig. 6

According to the mentioned figures (fig. 4, 5 and 6), Applicable Adaptronics is defined, according to the author, thus:

- is «the technical-technological merging and integrative system between research-development- innovation-industrial and commercial application and active exchange of experiences and transfer of knowledge with the latest solutions of products and systems for components and adaptive structures and current, evolving and generative trends».

- is «a combination of synergistic and integrative technical and intelligent technology known as intelligent systems, intelligent materials, intelligent processes, describing how easy adaptive systems and structures integrated with target reduction of material, energy and technology can be built, for implementation and operation to an absolute minimum, with applicative scenarios and scenarios focused on trying to simulate nature and man and vital functions, the ability of biological systems to recognize and automatically correct the dysfunctions of their own structure» (as this feature is desired in the first place by all technical structures and systems in areas with vital safety).

\section{EXAMPLES OF APPLIED ADAPTRONIC AND STRUCTURAL INTELLIGENT}

\section{CONSTRUCTIONS}

Intelligent Adaptronic Systems for integrated measurement and control for the automotive industry transferred to SC Automobile Renault-Dacia SA Pitesti, (fig. 7) 


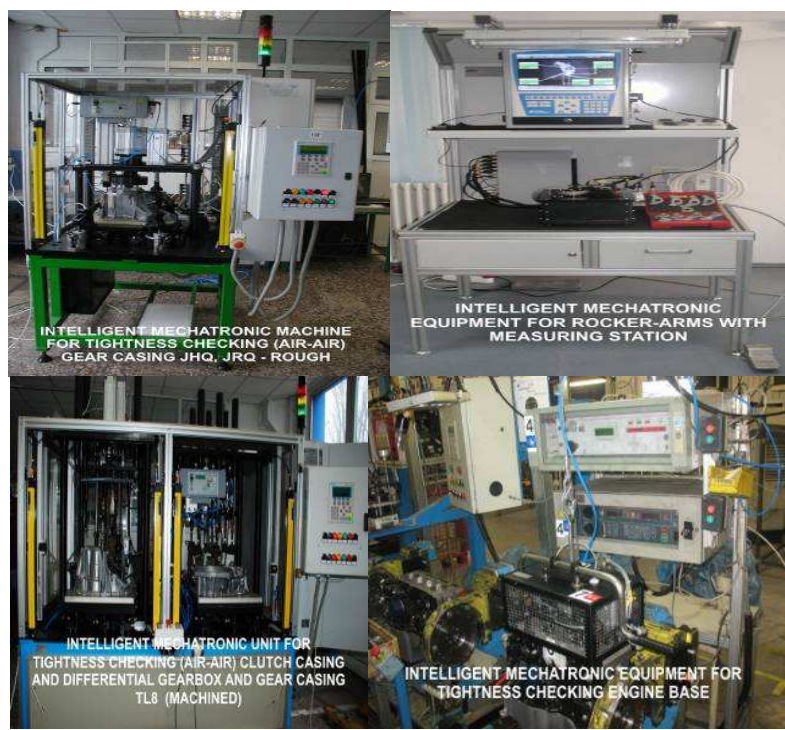

Fig.7

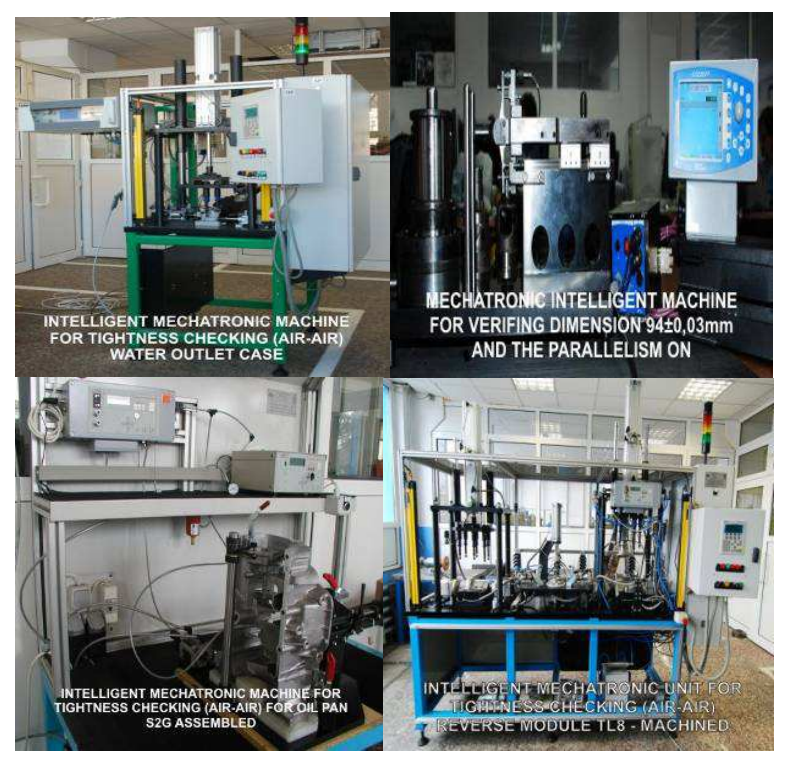

Fig.7 (continuation)

-Intelligent Adaptronic Systems for tele-monitoring and telemaintenance (fig. 8) Presented intelligent adaptronic systems (fig. 7) are based on, constructively, technolgically and in adaptative adaptronic mixture solutions ,flexibile intelligent automated platforms" adaptative to the geometry of the mark to be measured and checked and ,,dedicated programmes and assembled selectively-automated".

Thus, an intelligent adaptronic system, by automated selelecting and adaptation of thearchitecture of the intelligent platform, according to the geometry of the the volume of the piece to be measured and by selecting and activating the dedicated software programme corresponding to the geometry of the mark, can accomplish the measurement and checking of the air-air tightness, for the following mark: ,cylinder head machined", for a diversity of marks in the same family of marks (ex.: H4 Bt 80, H4 DA 490 ,H4 Bt 490 ,H4 Bt 490 Sulev) and for the mark ,distribution carter - machined” for a diversity of four marks in the same family (ex.: $\mathrm{H} 4 \mathrm{Bt} 80, \mathrm{H} 4$ DA 490 ,H4 Bt 490, H4 Bt 490 Sulev).

The structure of intelligent adaptronic systems for measuring and integrated control is architectured for the "automatic adaptive intelligent flexible platform" only according to the geometry of the part to be measured and verified, as follows:

creation of a structural matrix covering all geometries of measured and verified parts, based on both geometry and volume of each individual mark and a flexible kinematics with drive command on the geometry of ecah individual mark.

technical and technological construction of the intelligent adaptative automated flexible platform basing on the created structural matrix.

integration of dedicated and assembled selectively and automatically software select in the process of command and control, preparation, measurement, decision, marking and withdrawing the measured piece;

execution of the measurement, decision-marking and withdrawing the measured piece on the same mechatronic equipment;

elaboration of the measuring-checking process for each mark, for the range of marks.

The adaptronic intelligent systems presented (in fig. 8) are based on new adaptive mechatronic technologies for remote monitoring and configuration of process data in order to provide real-time intelligent teleservice function and remote control, remote monitoring and remote maintenance, these activities being aimed so ensuring optimum operating parameters nominal values and minimizing troubleshooting time and cost, rapid identification of errors and development of preventive in-processes strategies.

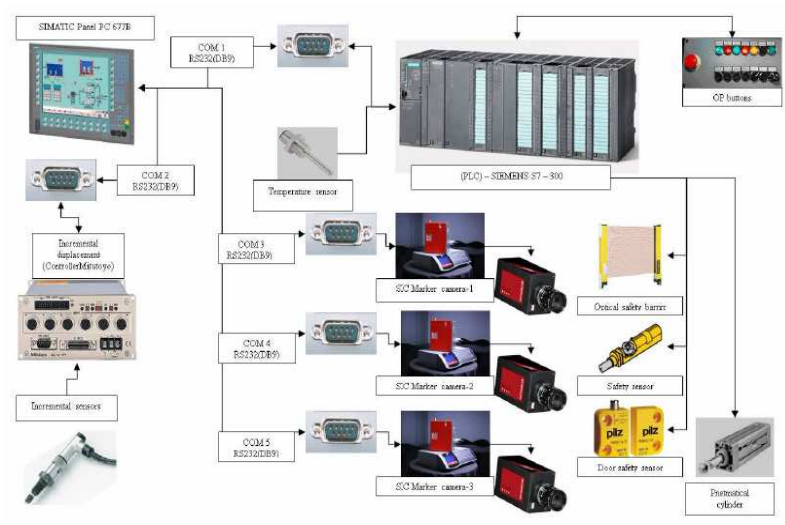

Fig. 8 
Based on the experimental model already realized by INCDMTM, performed samples and tests document the real possibility of remote control of mechatronic equipments (shown in Figure 7) implemented at SC. Automobiles RenaultDacia SA.

Thus, by using these adaptronic telemonitoring and remote maintenance systems applied to the automotive industry, errors can be corrected remotely yielding significant savings if there are considered a large number of intelligent adaptronice measurement and control system for automotive parts of the automobile manufacturer Renault-Dacia Pitesti.

To this end, control can be accomplished through regular Internet network but it requires the right beneficiary access to the internal network and to the mobile network, using GPRS protocol with equipment owned by the user and requiring an additional subscription to a provider of such services (e.g. Orange Romania SA, used already during experimentation).

In applying these intelligent adaptronic systems for telemonitoring and remote maintenance, are considered the security requirements of the data the users with remote access must ensure always that they have carefully selected and used the appropriate procedures to prevent data corruption and avoidance of loss and unauthorized access.

As immediate development of these intelligent adaptronic systems, are forseen the future research directions:

- development of the own application type "Teleservice Center Manager" of INCDMTM;

- direct connection to any device that uses Siemens PLC directly with STEP 7 development environment;

- extending of the mobility service by deploying a mobile platform type SmartPhone or Tablet PC, based on Android and WinCE operating systems.

\section{CONCLUSIONS - IT TAKES «REFLECTION»!}

The multi-integrative engineering of Mechatronics Integronics - Adaptronics is the newest engineering developed and destined to the XXIst century!

This new engineering, as any NEW thing, is accepted more and more in time and according to its applications in economy, industry and society!

\section{BIOGRAPHIES}

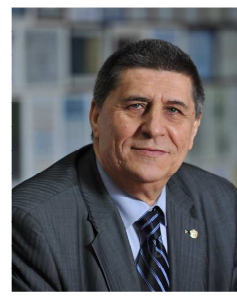

Prof. PhD Eng EurEng GHEORGHE I. GHEORGHE , Graduate (1970) Faculty of TCM, Department of Mechanics, Graduate (1992-1993, 1993, 1994, 1995, 1978, 1998, 2006) of graduate courses of Manufacturing Marketing, Planning, Financing, Investment Costs and Calculation, Management and Organization, Project Management, Leadership, Creativity, Quality Management, Auditing, International Economic
Relations in Germany, Austria and Romania, Doctor in Technical Sciences (Mechanics, Mechatronics and Robotics), (1978), UP Timisoara - Romania, Associate Professor (19712013) in the University "Politehnica" of Bucharest - Romania, (2000-2013) University "Valahia" of Targoviste - Romania and (2007-2013) Titu Maiorescu University - Bucharest, Romania, General Manager of INCD-Mechatronics and Measurement Technique - Bucharest, Romania; scientific doctorates coordinator (2010-2013) in Doctoral School Mechanical Engineering in University "Valahia" - Targoviste Romania, Author (main author or in collaboration with others) of more than 44 scientific and academic books and over 400 national and international scientific papers [including ISI (35)].

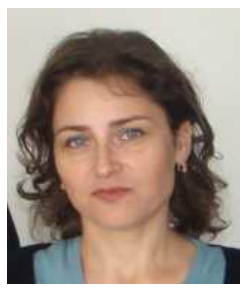

Simona ISTRIŢEANU, From 2010 to present: PhD stundent, 3rd year of study in the Doctoral School in University "Valahia“" of Targoviste, Field: Mechanical Engineering; 2008-2011- Graduate of the Academy of Economical Studies in Bucharest, Faculty of Economic Management; 1990 - 1995: University "Politehnica Bucuresti", Facultaty of Engineering and Technological Systems Management, Bachelor's Degree in Industrial Robots Specialization.

Relevant professional experience: $2005 \div$ currently, Head of the Internal Audit Department - INCDMTM, $2004 \div$ present: Researcher at the National Institute of Research in Precision Mechanics, 1995-2004: Engineer in SC AUTOMATICA S.A. Bucharest - Manipulators and Industrial Robots Design Department 